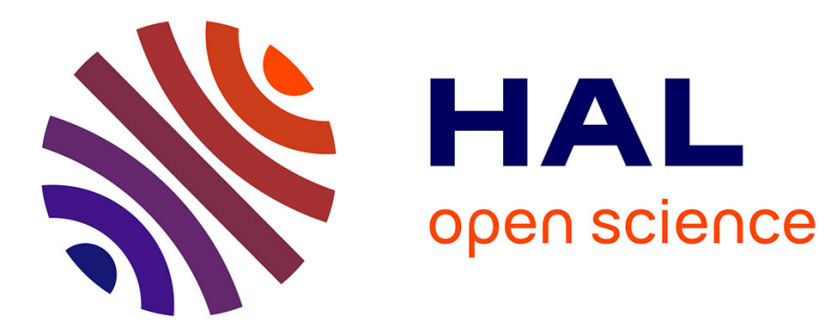

\title{
Modes of Hydrogen Incorporation in Hydrogenated Amorphous Carbon (a-C:H), Modifications with Annealing Temperature
}

Y. Bounouh, K. Zellama, Andreas Zeinert, M. Benlahsen, M. Clin, M. Thèye

\section{- To cite this version:}

Y. Bounouh, K. Zellama, Andreas Zeinert, M. Benlahsen, M. Clin, et al.. Modes of Hydrogen Incorporation in Hydrogenated Amorphous Carbon (a-C:H), Modifications with Annealing Temperature. Journal de Physique III, 1997, 7 (11), pp.2159-2164. 10.1051/jp3:1997248 jpa-00249707

\section{HAL Id: jpa-00249707 https://hal.science/jpa-00249707}

Submitted on 1 Jan 1997

HAL is a multi-disciplinary open access archive for the deposit and dissemination of scientific research documents, whether they are published or not. The documents may come from teaching and research institutions in France or abroad, or from public or private research centers.
L'archive ouverte pluridisciplinaire HAL, est destinée au dépôt et à la diffusion de documents scientifiques de niveau recherche, publiés ou non, émanant des établissements d'enseignement et de recherche français ou étrangers, des laboratoires publics ou privés. 


\title{
Modes of Hydrogen Incorporation in Hydrogenated Amorphous Carbon (a-C:H), Modifications with Annealing Temperature $\left(^{*}\right)$
}

\author{
Y. Bounouh $\left({ }^{1}\right)$, K. Zellama $\left({ }^{1, * *}\right)$, A. Zeinert $\left({ }^{1}\right)$, M. Benlahsen $\left({ }^{1}\right)$, M. Clin $\left({ }^{1}\right)$ \\ and M.L. Thèye $\left({ }^{2}\right)$ \\ $\left({ }^{1}\right)$ Laboratorre de Physique de la Matière Condensée, Faculté des Sciences d'Amiens, \\ 33 rue Saint-Leu, 80039 Amens Cedex, France \\ $\left({ }^{2}\right)$ Laboratorre d'Optıque des Solides $\left({ }^{* * *}\right)$, Unıversité Pıerre et Marie Curıe, 4 place Jussieu, \\ 75252 Parıs Cedex 05, France
}

(Recelved 4 February 1997, revised 30 June 1997, accepted 11 August 1997)

PACS.78.20.-e - Optıcal properties of bulk materıals and thın films

PACS.78 30.-J - Infrared and Raman spectra

PACS 78.30.Ly - Disordered solids

\begin{abstract}
In order to obtain more information about the nature of the hydrogen bonding and the thermal stability of $\mathrm{a}-\mathrm{C}: \mathrm{H}$ films, we have studied two different types of films labeled I and II deposited in a d c. multipolar plasma system from pure methane at substrate bias equal to -40 and $-600 \mathrm{~V}$ respectively A combination of several complementary techniques has been carried out on the samples in their as-deposited state as well as after isochronal annealing cycles at increasing temperatures up to $650^{\circ} \mathrm{C}$ The results clearly indicate that the two types of samples have very different $\mathrm{H}$ bonding and microstructure in their as-deposited state. They also behave differently upon annealing and still exhibit quite different microstructures and $\mathrm{H}$ bonding configurations up to high annealing temperature.
\end{abstract}

\section{Introduction}

Contrarily to hydrogenated amorphous silicon films in which only $\mathrm{sp}^{3} \mathrm{Si}$ atoms are present, in a-C. H samples carbon can take either $\mathrm{sp}^{3}$ (like in diamond) or $\mathrm{sp}^{2}$ (like in graphite) electronic configurations The hydrogen incorporated in the film is known to control the respective proportion of $\mathrm{sp}^{2}$ and $\mathrm{sp}^{3}$ sites. These two parameters are found to be deeply dependent on the method and the conditions of deposition, especially the impact energy of the film-forming species during growth It is also clearly established that the balance between the $\mathrm{sp}^{2}$ and $\mathrm{sp}^{3}$ hybridizations of the $\mathrm{C}$ atoms and the amount of $\mathrm{H}$ present in the samples are of crucial importance for the electronic and mechanical properties of the amorphous films $[1,2]$.

The aim of this paper is to contribute to a better understanding of $\mathrm{H}$ incorporation and its influence on the microstructure of the material. We thus present a detailed study performed on

$\left({ }^{*}\right)$ This paper was presented at the "Journées Maghrébınes sur les Sciences des Matériaux" held at Hammamet the 8, 9 and 10 November 1996

$\left({ }^{* *}\right)$ Author for correspondence

$\left({ }^{* * *}\right)$ UA 781 (CNRS), Case 80

(C) Les Éditions de Physique 1997 
two types of films deposited by the d.c multipolar plasma method at different substrate bias Using infrared absorption (I.R.) measurements, we characterize all the samples in therr asdeposited state and after successive annealing cycles at increasing temperatures. These results are discussed as a whole and are correlated with those obtained from optical tranmission, photothermal deflexion spectroscopy (PDS), and conductivity experiments.

\section{Experimental Details}

Two series of a-C: $\mathrm{H}$, labeled I and II, 0.6-0.7 $\mu \mathrm{m}$ thick, were prepared from pure methane in a d.c. multipolar plasma system at a substrate temperature of about $50{ }^{\circ} \mathrm{C}$ The substrate bias was equal to -40 and $-600 \mathrm{~V}$ for series I and II respectively. As previously reported [3], this important parameter determines the impact energy of the film-forming particles and consequently strongly influences the amount of $\mathrm{H}$ incorporated in the films as well as their microstructure. The films were deposited simultaneously on crystalline silicon and quartz substrates.

The total $\mathrm{H}$ content was checked by Elastıc Recoil Detection Analysis (ERDA) measurements. The $\mathrm{H}$ bonding was studied by I.R. experiments over a large frequency range, from 500 to $4000 \mathrm{~cm}^{-1}$. A combination of optical transmission and PDS measurements was carried out over the $0.7-2.5 \mathrm{eV}$ spectral range, in order to determine the optical gap $E_{04}$ as well as the refractive index $n$ at $2 \mu \mathrm{m}$ and the film thickness $d$ These experıments were completed by dark electrical conductivity measurements performed at room temperature in coplanar configuration. All these experıments were applied to the two types of samples in their as-deposited state and after annealing steps at increasing temperatures. The annealing cycles were performed in a quartz tube evacuated to $10^{-6}$ Torr, using a heating rate of about $20^{\circ} \mathrm{C} / \mathrm{min}$, and isochronal annealing times of $30 \mathrm{~min}$

\section{Results and Discussion}

We present in Figures $1 \mathrm{a}$ and $1 \mathrm{~b}$ typical I.R. spectra in the $\mathrm{C}-\mathrm{H}$ stretching region obtained in the as-deposited state for series I and series II respectively. The absorption bands were decomposed into Gaussian components which correspond to the different possible vibrational modes of the $\mathrm{C}-\mathrm{H}$ bonds $[4,5]$ The total integrated intensity of the whole stretching band is larger by about a factor 5 for series I, indicating the presence in this series of much higher bonded $\mathrm{H}$ content than in series II, in qualitative agreement with the ERDA data. This result is consistent with the fact that the amount of $\mathrm{H}$ incorporated $\mathrm{n}$ the films decreases as the negative bias increases in absolute magnitude, as previously reported $[3,6]$.

In the frequency range below $3000 \mathrm{~cm}^{-1}$, which corresponds to the contribution of $\mathrm{H}$ bonded to $\mathrm{sp}^{3}-\mathrm{C}$ sites, Figure 1 suggests that in both series, $\mathrm{H}$ is present in $\mathrm{CH}_{3}$ groups (sub-bands at 2870 and $2960 \mathrm{~cm}^{-1}$ ) as well as in $\mathrm{CH}_{2}$ units (sub-bands at 2855 and $2920 \mathrm{~cm}^{-1}$ ). In the frequency range above $3000 \mathrm{~cm}^{-1}$, which is assigned to $\mathrm{H}$ bonded to $\mathrm{sp}^{2}-\mathrm{C}$ sites, Figure 1 indicates that the fraction of $\mathrm{H}$ bonded to these sites is much more important for series II, approximately $23 \%$ of the total bonded $\mathrm{H}$ compared to $7 \%$ only in series $\mathrm{I}$. Moreover, it can be seen that $\mathrm{H}$ is incorporated as olefinic chains (sub-band around $3000 \mathrm{~cm}^{-1}$ ) and aromatic rings (sub-band around $3050 \mathrm{~cm}^{-1}$ ) in series II, while only olefinic configurations are present in series I. Although oscillator strength effects may influence the intensity of the I.R. absorption bands, $\mathrm{H}$ is therefore bonded preferentially to $\mathrm{sp}^{3}-\mathrm{C}$ sites. This tends to show that deposition conditions which lead to the incorporation of large $\mathrm{H}$ content favour the formation of $\mathrm{sp}^{3}-\mathrm{C}$ sites $[1,7]$ (series I). This difference between the two types of films is confirmed by the I.R. spectra in the low frequency range (below $1800 \mathrm{~cm}^{-1}$ ). In series II one observes a well defined 

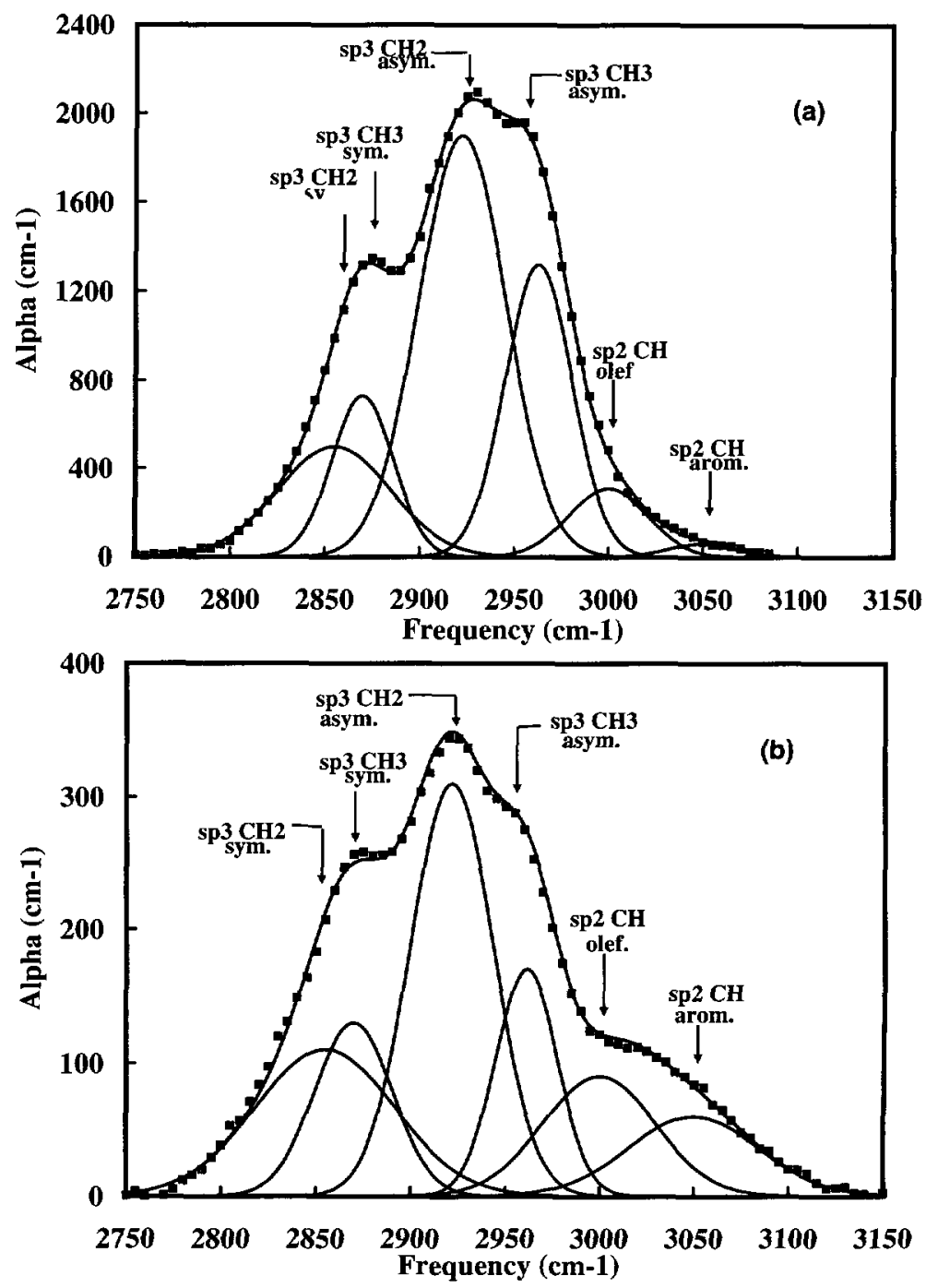

Fig 1. - Typical I R. absorption bands in the C-H streching modes for series I(a) and series II(b) samples in their as-deposited state; the positions of the different gaussian components corresponding to the different $\mathrm{CH}_{x}$ groups are indicated on the figure.

band centred around $1580 \mathrm{~cm}^{-1}$ and absorption peaks below $900 \mathrm{~cm}^{-1}$. The first band corresponds to $\mathrm{C}=\mathrm{C}$ double bond stretching modes [4,5], which confirms that this series contains a large fraction of $\mathrm{sp}^{2}-\mathrm{C}$ sites bonded to $\mathrm{H}$ or to other $\mathrm{C}$ atoms in various configurations. The bands below $900 \mathrm{~cm}^{-1}$ are related to out-of-plane deformation vibrations of aromatic sp ${ }^{2} \mathrm{CH}$ groups, in agreement with the presence of aromatic rings in this series $(\mathrm{C}-\mathrm{H}$ stretching band at $3050 \mathrm{~cm}^{-1}$ ). Both features are on the contrary hardly detectable in the I.R. spectra of series $I$, which in turn exhibits a well defined strong doublet at $1375-1455 \mathrm{~cm}^{-1}$, as well as two additional broad bands centred around 1700 and $1060 \mathrm{~cm}^{-1}$ which are observable only in this series. The doublet is characteristic of the presence of an important concentration of $\mathrm{sp}^{3}-\mathrm{CH}_{3}$ units, there must also be some contribution to the $1455 \mathrm{~cm}^{-1}$ component from sp ${ }^{3}-\mathrm{CH}_{2}$ groups $[8,10]$. This is an additional indication that in series $\mathrm{I}, \mathrm{H}$ is essentially bonded to $\mathrm{sp}^{3}-\mathrm{C}$ sites. This 
doublet must be present in series II which also contains a large proportion of $\mathrm{sp}^{3}-\mathrm{CH}_{3}$ groups. but it is almost completely buried into a wide and intense absorption band $\left(1000-1500 \mathrm{~cm}^{-1}\right.$ ) which may be assigned to vibrations of the highly connected $\mathrm{C}$ skeleton [8-10]

The additional 1700 and $1060 \mathrm{~cm}^{-1}$ bands observed in series I clearly suggest a high contamination by oxygen and water $(\mathrm{C}=\mathrm{O}, \mathrm{C}-\mathrm{O}$ bond stretching modes), and can be related to a wide band appearing around $3450 \mathrm{~cm}^{-1}(\mathrm{O}-\mathrm{H}$ groups). This result indicates that the samples of series I present a strong open porosity, which is in agreement with the very low value, about 1.54, obtained for the refractive index $n$ On the contrary, for serles II $n$ is about 1.92, suggesting that these samples are already more dense. The "polymeric" character of series I also explains the quite high value of its optical gap $E_{04}=3.3 \mathrm{eV}$. Series II also exhibits a high value for $E_{04}=2.9 \mathrm{eV}$, which is much higher than the value expected for films having a smaller $\mathrm{H}$ content and a larger concentration of $\mathrm{sp}^{2}-\mathrm{C}$ sites $[8,11]$. This can be explained by the fact that $E_{04}$ was determined from optical transmission measurements on samples deposited on quartz substrates; these substrates being insulators, contrarily to the slightly doped c-Si substrates used for the I.R. measurements, they might not be at the same effective potentiel as the c-Si substrates for strong negative bias $(-600 \mathrm{~V})$, which certainly leads to a different deposited material.

The effect of annealing on the $\mathrm{C}-\mathrm{H}$ bonding is illustrated in Figures $2 \mathrm{a}$ and $2 \mathrm{~b}$ by the modifications of the I.R. spectra in the $\mathrm{C}-\mathrm{H}$ stretching frequency range obtained for series I and series II after each annealing step respectively. For series I, the contribution of the $\mathrm{C}-\mathrm{H}$ bonds on $\mathrm{sp}^{3}-\mathrm{C}$ sites (below $3000 \mathrm{~cm}^{-1}$ ) first decreases moderately at $200{ }^{\circ} \mathrm{C}$ and $300{ }^{\circ} \mathrm{C}$, then more abruptly at $400{ }^{\circ} \mathrm{C}$ and $500{ }^{\circ} \mathrm{C}$. The $\mathrm{H}$ release from the $\mathrm{C}-\mathrm{H}$ bonds therefore starts at a temperature as low as $200^{\circ} \mathrm{C}$ A surprising result is however obtained at and above $400^{\circ} \mathrm{C}$, where the contribution of the $\mathrm{C}-\mathrm{H}$ bonds on $\mathrm{sp}^{2}-\mathrm{C}$ sites $\mathrm{m}$ aromatic configurations $\left(3050 \mathrm{~cm}^{-1}\right)$ starts to increase, suggesting that $\mathrm{sp}^{3}-\mathrm{C}$ sites are transformed into $\mathrm{sp}^{2}-\mathrm{C}$ sites without losing their $\mathrm{H}$, and that aromatic rings are formed, both as a result of this process and at the expenses of $\mathrm{sp}^{2}-\mathrm{CH}$ olefinic configurations which are almosit completely eliminated at $500^{\circ} \mathrm{C}$. At this annealing temperature there is still an important concentration of $\mathrm{H}$ bonded to $\mathrm{sp}^{3}-\mathrm{C}$ sites in $\mathrm{CH}_{2}$ and $\mathrm{CH}_{3}$ groups and to $\mathrm{sp}^{2}-\mathrm{C}$ sites in aromatic configurations. For series II, the absorption bands below $3000 \mathrm{~cm}^{-1}$ are almost unchanged up to $300{ }^{\circ} \mathrm{C}$. suggesting a higher thermal stability of these samples. Then the $\mathrm{H}$ fraction bonded to $\mathrm{sp}^{3}-\mathrm{C}$ sites starts to decrease slowly at $400{ }^{\circ} \mathrm{C}$ and almost vanishes at $500{ }^{\circ} \mathrm{C}$. On the other hand, the olefinic $\mathrm{sp}^{2}-\mathrm{CH}$ configurations are partially eliminated at $400^{\circ} \mathrm{C}$, and at $500^{\circ} \mathrm{C}$ only the contribution of aromatıc $\mathrm{sp}^{2}-\mathrm{CH}$ groups is still observable, with about the same intensity.

We observed the expected trends in the values of the optical gap $E_{04}$ (obtained from PDS) which decrease as the $\mathrm{H}$ content decreases Furthermore, as $\mathrm{H}$ evolves out. the films of both series become more dense. This is clearly evidenced by the increase of the $n$ value and the decrease of the $d$ value (obtained from the optical transmission) as the annealing temperature increases However, the samples of series II remain more compact than those of series I.

Another important difference in the annealing behaviour between series I and serles II is deduced from the variations with annealing temperature of the room temperature electrical conductivity $\sigma$. It stays almost constant up to $400^{\circ} \mathrm{C}$ for series I and $500^{\circ} \mathrm{C}$ for series II. It then increases slowly up to $550^{\circ} \mathrm{C}$ and abruptly at higher temperature up to $650^{\circ} \mathrm{C}$ (by about 4 orders of magnitude), for series I, while for series II, it increases rapidly and continuously up $650^{\circ} \mathrm{C}$ (by about 7 orders of magnitude). These results suggest that in series II the $\mathrm{C}$ network is then strongly connected with a high proportion of $\mathrm{sp}^{2}-\mathrm{C}$ sites, possibly organized in graphitic clusters [12]. 

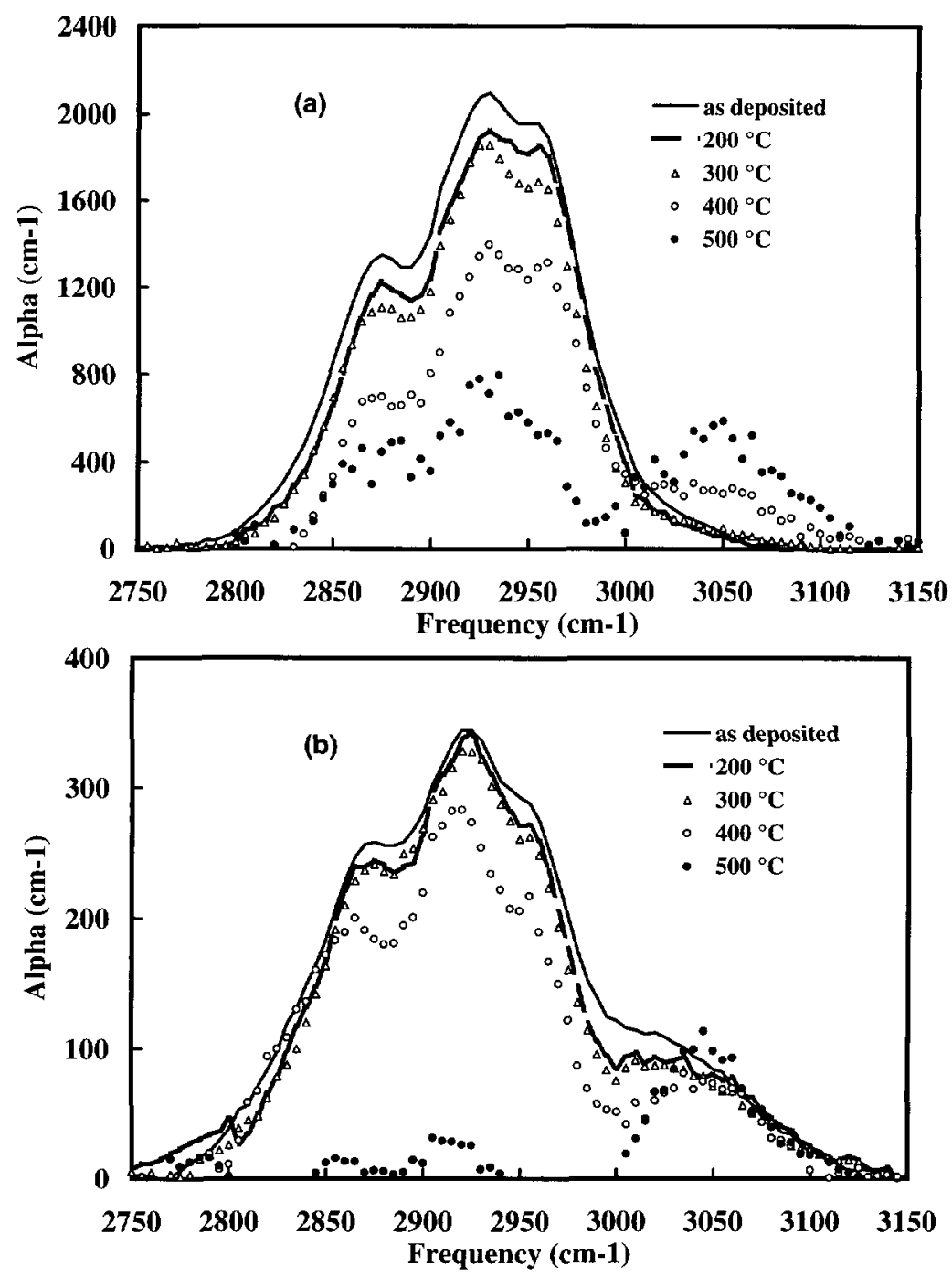

Fig 2. - Modifications of the different $\mathrm{C}-\mathrm{H}$ stretching bands after each annealing step obtained for series $\mathrm{I}(\mathrm{a})$ and series II(b)

\section{Conclusion}

From this systematic study carrıed out on two series (I and II) of a-C : H films deposited respectively at -40 and $-600 \mathrm{~V}$ in a d.c. multipolar plasma system using pure methane, we showed that in the as-deposited state the two types of samples exhibit very different $\mathrm{H}$ incorporation and microstructure. A high $\mathrm{H}$ content essentially bonded to $\mathrm{sp}^{3}-\mathrm{C}$ sites and a very small proportion of $\mathrm{sp}^{2}-\mathrm{C}$ sites essentially in olefinic configurations are present in the low bias series I, while the high negative bias series II contains a large proportion of nonhydrogenated as well as hydrogenated $\mathrm{sp}^{2}-\mathrm{C}$ sites in both olefinic and aromatic configurations, and a smaller $\mathrm{H}$ content bonded to $\mathrm{sp}^{3}-\mathrm{C}$ and $\mathrm{sp}^{2}-\mathrm{C}$ sites Annealing also affects differently the two types of films. They still exhibit quite different $\mathrm{H}$ bonding and microstructures at 
annealing temperature as high as $500{ }^{\circ} \mathrm{C}$. At this temperature, series I retains a large $\mathrm{H}$ content bonded both to $\mathrm{sp}^{3}$ and $\mathrm{sp}^{2}$ (aromatic) $\mathrm{C}$ sites, while series II has a low $\mathrm{H}$ amount, bonded only to $\mathrm{sp}^{2}-\mathrm{C}$ sites in aromatic configurations. The release of $\mathrm{H}$ makes the two types of films more dense, with, however, a higher compactness for the samples of series II

\section{Acknowledgments}

The authors would like to thank J. Perrière and A. Laurent (G P S. Université Parıs 7) for the samples preparation and ERDA measurements

\section{References}

[1] Robertson J., Amorphous carbon, Adv. Phys. 35 (1986) 317-374.

[2] Tang X.M., Weber J., Baer Y., Muller C., Hannı W. and Hintermann E, Influence of hydrogen on the structure of amorphous carbon, Phys. Rev B|48 (1993) 10124-10128.

[3] Perrière J , Siejka J., Enard J.P., Laurent A. and d'Heurle F.M., Low temperature plasma anodization of silicides, Mat. Res. Sympos. Soc. 38 (1984) 443-447.

[4] Koidl P., Wild C, Dischler B., Wagner J. and Ransteiner R., Plasma deposition properties and structure of amorphous hydrogenated carbon films, Mar:Sci. Forum 52-53 (1989) 41-70.

[5] Dischler B., Bubenzer A.and Koidl P., Bonding in hydrogenated carbon studied by optical spectroscopy, Solzd. State Com. 48 (1983) 105-108.

[6] Spousta J., Perrière J., Laurent A., Fogarassy E, Prevot B. and DE Umano S., Laser induced modifications in a-C:H thin films, Appl. Surf. Scr. 69 (1993) 242-248.

[7] Tersoff J., structural properties of $\mathrm{sp}^{3}$-bonded hydrogenated amorphous carbon, Phys. Rev. B 44 (1991) 12039-12042.

[8] Bonouh Y., Thèye M.L., Dehbi-Alaoui A., Matthews and Stoquert J.P., Influence of annealing on the hydrogen bonding and the microstructure of diamondlike and polymerlike hydrogenated amorphous carbon films, Phys. Rev. B 51 (1995) 9597-9605.

[9] Bellamy, The infrared Spectra of complex molecules, Vol. 2 (Chapman and Hall, London, 1975).

[10] Lukins P.B., McKenzie D.R., Vassalo A.M. and Hann J.V., Carbon 31 (1993) 569.

[11] Dixit P.N., Kumar S., Sarangi D. and Bhattacharyya R., Onset of photoconduction in hydrogenated amorphous carbon films prepared by asymmetric PECVD technique, Solvd State Com. 90 (1994) 421-423.

[12] Robertson J., Clustering and gap states in amorphous carbon, Phil. Mag. Lett. 57 (1988) 143-148. 